\title{
Encounter with the Demonic: Western, Eastern, and Object Relations Approaches
}

\author{
Kevin Volkan 1,2 (이 \\ ${ }^{1}$ Department of Psychology, California State University Channel Islands, Camarillo, CA, USA \\ ${ }^{2}$ Graduate Medical Education Program, Community Memorial Health System, Ventura, CA, USA \\ Email: kevin.volkan@csuci.edu
}

How to cite this paper: Volkan, K. (2020) Encounter with the Demonic: Western, Eastern, and Object Relations Approaches. Psychology, 11, 1454-1470.

https://doi.org/10.4236/psych.2020.119092

Received: August 28, 2020

Accepted: September 26, 2020

Published: September 29, 2020

Copyright $\odot 2020$ by author(s) and Scientific Research Publishing Inc. This work is licensed under the Creative Commons Attribution International License (CC BY 4.0).

http://creativecommons.org/licenses/by/4.0/

\section{(c) (i) Open Access}

\begin{abstract}
The idea that humans can be inhabited by supernatural entities is widespread among cultures and religions around the world. Demonic possession is sometimes encountered by clinicians who choose to understand it as the actual presence of a demon possessing a human, or as a psychological phenomenon. Some forms of Christianity hold to the belief that demonic possession occurs in reality. Clinicians who share these beliefs may abandon a psychological understanding and treatment of the phenomenon in favor of religious explanations and rituals. Eastern religions like Buddhism understand demonic possession as relatively real but also see it as ultimately stemming from psychological issues. Psychoanalysis understands demonic possession as the result of interpsychic processes related to disturbances in the development of early internalized object relations. This has a number of implications for treatment of so-called demonically possessed individuals, which is exemplified in two clinical cases.
\end{abstract}

\section{Keywords}

Demonic Possession, Devil, Exorcism, Object Relations, Projection, Psychoanalysis

\section{Introduction}

For clinicians it is sometimes difficult to be purely objective. There are patients who seemingly defy our attempts at explanation, and present in baffling ways. Some of these patients seem as if their motivation comes not from their own 
sense of self but from somewhere else. Before the advent of the concept of mental health, such people were often deemed to be possessed.

I must admit to being skeptical of the idea of demonic possession. I never really thought much about it until I had two patients that presented as if they were inhabited by demons. If it were not for my own clinical experience, I would be content to leave the subject as a historical footnote. Nevertheless, the literature on the subject is interesting in its own right and deserves treatment. This literature is quite vast, and I will only touch upon a few examples here.

\section{Demons in the Western World}

Nearly all religious and spiritual traditions around the world contain descriptions of spiritual beings that occasionally interact with humans for nefarious purposes. The phenomenon of possession is found throughout the world and is often associated with shamanic beliefs and practices (Eliade, 2004). Western religions, many of which have shamanic origins, are replete with examples of possession. The ancient Greeks with their Delphic Oracle of Apollo, Northern Eurasian indigenous religions, the so-called Zar cult of Ethiopia, and Old Testament spirits are but a small sample (Van den Stock et al., 2012). The female followers of Dionysus, known as Maenads, lived very chaste lives, but would become violently possessed under the influence of wine (K. Volkan, 1994).

The Bible (Carroll \& Prickett, 2008) contains a number of descriptions of possession. In some cases, biblical demons give a person superhuman strength, but also cause them to injure themselves, suffer from deafness and blindness, as well as general weakness and arthritis. These examples, drawn from the Wrested Scriptures website (Satan, Devils, \& Demons, n.d.) demonstrate that demonic possession in the light of Christianity can take on different meanings.

Slaten (1920) examined the different meanings of demonic possession in the Bible and derived three definitions. The first is allegorical, representing bad habits and inclinations such as lust, alcohol, and anger. The second definition includes medical and neurological conditions. The third definition is that demons are entities devoid of a physicality that must inhabit a body for the purposes of carrying out Satan's orders. Not all Christians agree with these definitions. The Catholic Church, for instance, only recognizes that last definition as true demonic possession (De exorcismis et supplicationibus quibusdam, 2004).

\section{Eastern Demonological Perspectives}

Western cultures are not the only cultures to describe demons that scourge humanity and that sometimes take possession of humans. Hinduism describes Rakshasas who are demons that plague humans in many different ways. They are perhaps most famously described in the Hindu epic the Ramayana that originated around the $4^{\text {th }}$ century B.C.E (Egenes \& Reddy, 2016). In this story Sita, the wife of Rama (who is an incarnation of the Hindu god Vishnu), is kidnapped by the demon Ravana and held on the island of Sri Lanka. Ravana's kidnapping 
of Sita is motivated by lust, but it is not clear whether he rapes her ${ }^{1}$. Interestingly, both Rama and Sita are avatars of the God and Goddess Vishnu and Lakshmi respectively. In a sense, as avatars Rama and Sita are possessed by powerful supernatural beings. Avatars are the embodiment of the essence of a supernatural being in another, presumably human form. The embodiment into an avatar is an ongoing process and a descent from the spiritual plane into the world (Hacker, 1978; Monier-Williams, 1872; Sheth, 2002). Since avatars are typically beings that act for the good of others, they can be thought of as representing a positive act of possession. Like many stories from the Eastern world, the Ramayana depicts supernatural beings, including demons, as having both good and bad qualities.

Two other examples come from Tibet. The first example is intertwined with the introduction of Buddhism to Tibet. The founder of Tibetan Buddhism, Padmasambhava was an Indian Buddhist master who was invited to Tibet. The country of Tibet at that time was plagued by demons and the king was motivated to bring in someone who could get rid of them. The native Bon religion of Tibet was shamanic and familiar with the concept of demons and possession. Padmasambhava accepted the king's invitation, went to Tibet and subdued the demons. $\mathrm{He}$ also did an interesting thing. Rather than just destroy these supernatural creatures, he reminded them that even though they had supernatural capabilities, they were still subject to the laws of karma and therefore would reap the fruits of their bad behavior. The demons were converted to Buddhism and become its protectors. These demons are known as dharmapalas. They retain their demonic qualities but use them to further the cause of Buddhism (Sidky, 2011).

The second example is the Tibetan State Oracle, known as the Nechung, who served the traditional Tibetan theocratic government. This oracle comes from a tradition of Shamanic Buddhism which was heavily influenced by the pre-Buddhist shamanic Bon religion of Tibet. The Nechung is a person who possibly demonstrates pre-cognitive abilities and dreams of the deity. The deity choses the oracle and they spontaneously go into a trance state. After the trance has worn off, the Nechung does not remember the experience. The person chosen as Nechung must then be ordained as a monk and undergo training in mental yoga. Through an elaborate meditative ritual, the Nechung is able to enter a trance state and allow himself to become possessed by a god known as Pehar. Through the medium of the Nechung, this deity advises the Tibetan government and helps in the search for reincarnations of important Tibetan religious leaders (Crook, 1998; Sidky, 2011). The Tibetan State oracle is another example of positive possession where the entity possessing a human does so to provide help to humanity.

\footnotetext{
${ }^{1}$ One reason Ravana may have refrained from raping Sita is because he had been cursed in the past for the rape of Apsara the intended of Nalakubera, who was the son of the powerful god of wealth. The curse was that if he ever forced himself upon a woman against her will his head would explode. Also, in many accounts Sita is thought to be able to protect herself, being the incarnation of Lakshmi. Therefore, after her capture Ravana tries to convince Sita to give herself to him willingly but is unsuccessful. In other accounts, the language used to describe Sita's abduction is thought to be evidence that Sita indeed had sex with Ravana, initially against her will but eventually willingly.
} 
In addition to providing examples of demonic possession, Buddhism can help in clarifying what demonic possession is and is not. The Buddhist faith holds two views of the reality or what it calls "truth" which comes from the Madhyamika school of Buddhist philosophy which was founded by Nagarjuna. A conventional or relative truth which is provisional to the existence of the phenomenal world, and an ultimate or absolute truth which is a reflection of the indeterminable nature or "emptiness of the phenomenal world" (Murti, 2013). Tibe$\tan$ Buddhism has applied this philosophy to its understanding of the demonic using the terms relative and the absolute for the two views. In the relative view supernatural beings like gods and demons are real entities with free agency. They have the ability to cause trouble, or conversely, they can be a force for the good. In the absolute view however, supernatural beings are seen as something created by our minds. For Buddhists the experience of demonic possession ultimately results from our own misunderstood emotions of anger and turmoil. This viewpoint is consistent with a Western psychological understanding of demonic possession (Clifford, 1996).

\section{Demonic Possession as a Real Phenomenon}

As in Buddhism, medical and mental health professionals ultimately understand demonic possession as something created by the mind of the possessed person that does not actually exist. Understanding the mind of a possessed person helps us formulate theories and treatments appropriate to the person's condition. However, when possession phenomena are encountered outside the medical or mental health professions, the so-called possessed person is often regarded as if they were inhabited by an actual demon. This may especially be true when the afflicted person is in a religious milieu or when standard treatments are ineffective.

Drawing from the work of Richards (1974), Prins (1990) suggests that true possession can be caused by a person experiencing occult phenomena, inviting a demonic entity to take control, and unknown causes where a person seems to have a talent for attracting demonic possession. More pragmatically useful for believers are the symptoms of demonic attack that support the view that demonic possession is something real. Prins lists these as the following:

1) Personality change, including an increase in intelligence.

2) Physical phenomena (for example, unusual strength, convulsions, anesthesia to painful stimuli).

3) Mental changes (evidence of an ability to understand previously unlearned languages and to speak "in tongues" or glossolalia, voice changes particularly a deepening and uncouthness.

4) Fear of, and antagonism towards, the divine (blasphemous phenomena) (p. 34).

Some, including the Catholic Church, who take possession literally have stated that the existence of demons is a rare but real phenomenon (De exorcismis et 
supplicationibus quibusdam, 2004). These individuals are for the most part religious believers whose religion focuses on an external battle between good and evil. If there is a force for good like God and Jesus, there must necessarily be a Devil as well as his demons. One of the most interesting commentators with direct experience with so-called possessed individuals is M. Scott Peck, who is both a psychiatrist and practicing Christian. Peck has a decidedly dichotomist Christian world-view-you are either serving God or serving Satan, and human free will is limited to choosing which side you want to be on.

In Peck's book (2005) Glimpses of the Devil: A Psychiatrist's Account of Possession, Exorcism, and Redemption, he reports on two cases of possession where he performed rites of exorcism. Peck makes the point that the women in these cases, Jersey and Beccah, respectively represent imperfect and almost perfect forms of possession. Jersey becomes possessed at a much later age and for a shorter period of time and therefore is able to be rid of her demons. Beccah, on the other hand, is possessed from an early age and stays that way for much of her life. Similar to most psychopathology, earlier origins of possession point to greater severity of symptoms.

Peck's book is well-written, but it is a work that comes with a specific, belief that must be taken as an article of faith-i.e. that the Devil exists. There are also demons who are under the control of the Devil and do his bidding. This Devil is a spirit that can manifest in many places at once and in a variety of ways. The Devil is malevolent and seeks to destroy humans, while demonstrating marked narcissism. He can take over the body, mind, or soul of susceptible or willing humans.

Peck's belief in the existence of a Devil and demons is rather remarkable for a psychiatrist who would be expected to understand demonic possession from a psychological perspective. Peck's intuition about the presence of demons inhabiting his patients is based mostly on his sense of an "other" within the people he is treating. In Peck's cases this "other" manifests greater strength, changes in appearance, changes in personality, and changes in intelligence. Yet, while rare, these symptoms are not unknown in psychiatry. Even though Peck is a psychiatrist there is nary a mention of dissociative disorders in his book ${ }^{2}$ (Rosik, 2005). One would assume he must have been exposed to the diagnostic categories of dissociative and personality disorders in his training. My sense is that Peck is choosing to understand the dissociation seen in his patients through the lens of Christianity, rather than through psychiatry. His patients might be suffering from borderline personality disorder, or psychosis, or depression, but once they manifest dissociation to the point where there is a sense of an "other", they must be possessed. This view limits treatment options to those that ascribe

${ }^{2}$ Peck's diagnoses seem a bit off. He initially diagnoses Jersey with borderline personality disorder even though her symptoms don't seem to fit this diagnosis. He later refers to her as acting somewhat psychotic. When Peck snaps her out of a supposed psychotic break, she seems to exhibit dissociative characteristics. 
to a belief in demons. As Peck points out, the treatment of choice becomes exorcism, which is an aggressive and invasive intervention, which has potential to psychologically and possibly even physically damage the patient.

\section{Demonic Possession as a Psychological Phenomenon}

As has been stated, the most obvious understanding of demonic possession in general is as a psychological problem. More specifically, demonic possession can be understood as a dissociative disorder, usually dissociative identity disorder (DID) which is itself and extreme example of the dissociative spectrum of mental illnesses. The prevalent theory is that dissociation occurs as a defensive response to overwhelming trauma that usually occurs in childhood. Trauma may occur in specific instances or may be long term and chronic. In DID the child has no refuge from the trauma and uses severe dissociation to escape from his or her harrowing experiences. When this sort of dissociation is repeated many times, or the child has a talent for dissociation, the dissociated experiences may coalesce into separate personality centers. The earlier in childhood the trauma occurs, the worse the dissociation. It is no surprise that many cases of demonic possession consist of people who have experienced childhood trauma in the forms of emotional, physical, or sexual abuse (Hansen et al., 1992; Hill \& Goodwin, 1993; Ivey, 1993). In this line of thinking the idea is that one or more alternate personalities (alters) can represent a demonic presence. The labeling of an alter as demonic is sometimes suggested to the DID sufferer, either by a therapist, counselor, clergy, or through popular culture/media, or printed material. Mass media may play an important role with films like The Exorcist (Friedkin, 1973) or novels like Come Closer (Gran, 2003) highlighting the experience of demonic possession.

Spanos, who has written extensively about DID and possession, also makes an excellent argument for the secondary gain the sufferer derives from a diagnosis of possession. This gain includes attention, excuse of behavior outside the cultural norm, and release of inhibitions (Spanos \& Gottlieb, 1979). Prins (1990) makes a similar case that some people value possession states because it allows them to avoid responsibility for certain behaviors that would be condemned or even punished in their culture. He goes on to suggest that there can be heightened suggestibility for possession derived from medical/psychiatric conditions as well as culturally specific experiences.

Anthropologist Bourguignon who studied possession in Haiti, comparing it with the famous DID case of Sybil, makes the case that demonic possession is not something learned through a culture:

"The great difference between such a patient and the characteristic Haitian cult initiate (or for that matter, a possession trancer in any of our 251 sample societies and many others as well) is that these dissociations are purely idiosyncratic; the behavior is not learned by following a cultural model. No one has attempted to teach dissociation." (Bourguignon, 1991: p. 38). 
Bourguignon's point is that DID patients do not train to become possessed by a specific entity that is a container for a number of different cultural clues. DID patients form idiosyncratic alters that are based around their own history and psychological needs. She points out that the sort of universalist possession states she describes in Haiti are rooted in an individual's psychology:

"And the very fact than an individual s first possession trance is usually spontaneous and involuntary suggests the personal psychological roots of this behavior...first possession trances generally occur at adolescence, suggesting a crisis of individual development." (p. 39).

In this way dissociative phenomena and demonic possession are based on a person's psychological makeup and developmental experience. In Haiti small children are indulged but as they get older, they are treated more harshly. In adolescence and young adulthood, when the individual begins to assert themselves, they experience unconscious conflict over performing behavior that was previously punished. This conflict results in the person having a first trance possession experience. This recalls the psychological dynamic in culture-bound disorders like Saora psychosis, where possession can be used by adolescents to express inner conflict over their external situation (Krippner, 2019; Turner, 1979).

\section{The Demonic Unconscious and Object Relations}

Psychoanalysis understands demonic possession as having something in common with the unconscious. As Freud put it, "the devil is certainly nothing else than the personification of the repressed unconscious instinctual 1ife" (Freud, 1908: p. 174). Both the demonic and the unconscious are repositories for socially unacceptable behaviors, both represent urges that seek to throw off repression, and both present in a highly symbolic fashion.

Ellenberger (1981) suggests that psychoanalysis is a form of primitive medicine, with the unconscious as a type of spirit possession and psychoanalysis as a variant of exorcism. Ivey (2002) also questions whether psychoanalysis is so fundamentally different than exorcism. The demonic, in the form of repressed urges, has the feeling of being dissociated from consciousness. The "exorcism" of psychoanalysis is to heal this dissociation, to bring about an encounter between the unconscious and what is conscious. This also entails working with the unconscious we project on to the world as demons can be both within and without. As Freud said;

"Spirits and demons... are only projections of man's own emotional impulses. He turns his emotional cathexes into persons, he peoples the world with them and meets his internal mental processes again outside himself.' (Freud, 1919: p. 152).

From within, or projected out, the demonic unconscious becomes an evil enemy, a monster, an "other" with nefarious purpose. Left unexamined it is likely to be more aggressive, hostile and dissociated.

Freud had a long-standing interest in the occult and wrote an important paper on demonic possession. This paper, A Seventeenth Century Demonical Neurosis (Freud, 1923) examines the psychodynamics in the case of the painter Christo- 
pher Haitzmann, who makes a pact with the devil soon after the death of his father. In this pact Haitzmann signs himself over body and soul to the devil after nine years. But at the end of this time Haitzmann becomes frightened and remorseful and is able to break his promise to Satan through the intercession of the Virgin Mary. Thereafter however, Haitzmann becomes persecuted by God and Christ and later joins the Church.

For Freud, demons in the external world are a projection of negative and unacceptably bad wishes that come from repressed urges. Freud interprets Haitzmann's pact with the Devil as an attempt to replace his lost father with whom he had an ambiguous relationship. The Devil, like God, has its origins in the child's ambivalence towards their father, who can be kind and caring or feared and hated. The Devil and God, for Freud, represent the child's projected experience of his or her father. Haitzmann's possession by the Devil is an attempt to gain a replacement for his father in order to assuage his depression. We can assume that Haitzmann invokes the Devil rather than God because his hostile and fearful attitude towards his father outweighed his more tender feelings towards him. Later Haitzmann is "saved" from his pact by the projection of the image of his mother on to God via the Virgin Mary. This is later supplanted by Christ as the substitute father. Haitzmann's eventual entrance into a religious order can been seen as resolving his oedipal complex by identifying with the God/father.

Ivey (1993) in his excellent paper on the Psychodynamic Aspects of Demonic Possession and Satanic Worship outlines an object relations understanding of demonic possession. Object relations is the branch of psychoanalysis that examines the way in which the relationships with early objects, who are caretakers (usually mother and then the father), are internalized as mental representations by the infant. During normal development the objects or part objects such as the breast, are experienced according to the vicissitudes of the drives. For instance, when the breast gives milk it is comforting, pleasurable and loved. When it is taken away or not offered the infant experiences frustration, anxiety, and hatred. Later on, these part objects become elaborated into whole objects, usually beginning with the mother or primary caretaker. She is consequently experienced as good and bad and internalized as good and bad object representations. These object representations are experienced separately but in normal development they become fused into a more realistic representation of the mother/caretaker. The mother/caretaker is then experienced ambivalently as both good and bad. However, if the infant's early experience is mostly frustrating, anxiety ridden, and hate filled, the internalized bad objects are kept separate from the good objects to protect them. As a defense mechanism the bad object representation is projected out to preserve the internalized good object and alleviate anxiety. The projected bad object representation becomes the external demon or Devil. If the person is unable to project out the representation of the bad object, the internalized bad object becomes the demon within who possesses the person. The lack of integration of the good and bad object representations leads to the experience of dissociation. If the infant is never able to fully integrate the good and bad ob- 
jects, the pattern of projecting out the bad object will persist into adulthood as is seen with people who have borderline personality organization. In cases of more severe trauma which results in dissociative disorders the object representations can coalesce into various dissociated personalities.

Ivey goes on to make an important distinction between involuntary and voluntary possession. People who feel themselves to be possessed against their will experience the symptoms of possession as egodystonic, producing acute anxiety. In this case the internalized bad object produces the egodystonic symptoms. There is the feeling the demonic presence is different from the person's self-awareness. The bad objects are so split off that they seem to take on a life of its own. They are experienced as "other" threatening to overwhelm the good, taking over the person's thoughts, motivations and behaviors. This causes a great deal of anxiety.

Conversely, some demonically possessed people have invited their possession. In these cases, there is an identification with the externally projected bad object. In voluntary possession there is an attempt to reclaim the externally projected bad object with whom the person has identified with. This may be an attempt to fuse it with the internalized good object. As such the person who becomes voluntarily possessed experiences symptoms as egosyntonic, at least initially. Once the bad object is internalized it may threaten to overwhelm the good object at which time the symptoms may morph from egosyntonic to egodystonic. In this way voluntary possession can go awry and become involuntary. It is quite possible that a person will oscillate back and forth between projecting and internalizing the bad object.

Many of the object dynamics of projection and internalization outlined above can be seen among cases of supposed demonic possession. This is true even when the so-called demonic presence experienced by clinical personnel is simply expressed as conspicuous personality and behavioral changes that are hostile and aggressive. Baseline verbal and cognitive abilities, as well as achievement of developmental milestones in such patients may play little or no role in their supposed demonic possession. The cases presented below exemplify this sort of clinical encounter with the demonic.

\section{Case Histories}

In my hospital practice I had two cases illustrative of many of the characteristics of demonic possession discussed above as well as some unique features. These cases were with patients I worked with for approximately three years.

\subsection{Jimmy}

Jimmy is a 23-year-old male of average height and weight, with a pale complexion and dark features. He has been institutionalized since the age of seven when his parents committed him to the state hospital. In his 16 years in the state hospital Jimmy's parents have never come to visit and do not maintain any contact with him. Unlike many of his fellow patients Jimmy's face is smooth and he 
could be called handsome. His eyes are set wide apart, with long eyelashes that seem almost feminine. Jimmy has so-called "cat's eye", an abnormality which looks like a split in the iris which is the colored part of the eye. Along with the wide spacing of his eyes, this gives Jimmy almost a cat or goat like appearance which many find vaguely discomforting.

Jimmy sometimes appears calm and reflective as if he is thinking about something. He also smiles to himself as if he is secretly amused. Nevertheless, his intelligence test scores label him as profoundly developmentally disabled and he unable to speak beyond making an occasional grunt or laugh. Jimmy suffers from a lack of motor coordination and typically walks or runs with little steps and frequently falls over. He also has some general muscle weakness.

Jimmy has a number of severe behavioral problems, including pica (eating non-food substances), stealing from other patients and staff, injuring himself by hitting his head against the wall, and physically assaulting others (especially women staff members). He responds poorly to the standard behavioral treatment program and there do not seem to be any clear behavioral antecedents. DNA testing shows that Jimmy suffers from congenital Ring 22 chromosome syndrome.

After an especially bad episode during which Jimmy assaulted a nurse on the unit, I decided to work intensively with him. After speaking with the unit nurses, I learned that the last assault was rather typical for Jimmy. They tell me that although Jimmy cannot move too quickly and is weak, he occasionally has episodes when he becomes aggressive. During these times he is able to move quite quickly, with a good deal of coordination, and he becomes exceptionally strong. The nurses also tell me that in this state Jimmy seems to have a malevolent intelligence that guides his actions so that he attacks with precision timing in a way to cause the most harm. Jimmy's attacks during these episodes are also interesting. He typically only attacks females with ample breasts in such a way as to corner them in a room alone where they cannot get away. He then grabs and pinches their nipples extremely hard with a painful twisting motion, while laughing loudly. His strength is such that during these attacks these strong women have a difficult time disengaging Jimmy and have to scream for help. All the nurses I talk to say that during these episodes Jimmy acts as if he is "possessed". After these attacks Jimmy becomes subdued and again becomes weak, unintelligent, and docile.

A functional analysis of Jimmy's behavior and a review of his chart does not turn up any clear behavioral antecedents, nor do I find that he is trying to communicate any needs to the staff. I decide to visit with him on the unit each day, take him on walks around the facility, and spend time with him in my office. After a short amount of one-to-one time with Jimmy I perceive that sometimes he goes into another personality state where he seems more aggressive, alert, intelligent, and for lack of a better word malevolent. This change is subtle and does not result in any specific behavioral problems with me, but the transformation is marked. Sometimes before going into this state Jimmy seems distracted or "spaced 
out" for a few seconds. In many of my patients this is a small epileptic fit and it may be that this is what is happening with Jimmy. Once in his alternate personality state Jimmy seems to be looking for trouble. I sense that he is looking for an opportunity to do mischief. During these periods I feel that I am in the presence of some kind of entity, which is quite disconcerting. I try to talk and reason with Jimmy and he often laughs mockingly at my attempts to communicate with him. I find these moments chilling and initially I began to dislike having to spend any time alone with him. Later on, I discover that when Jimmy is in these states, he likes chocolate and coffee and I use these to get him to interact with me. This allows us to spend time together somewhat companionably. Over coffee I feel less disconcerted and more comfortable in Jimmy's presence. I worry that he will be transferred to a unit specializing in severe behavioral problems where he will likely be attacked by other patients.

\subsection{Scott}

Scott is a tall, well-built 31-year-old man who has been institutionalized much of his life. He had a rough childhood being brought up by poor, uneducated white parents from the Midwest. His mother was schizotypal, and his sister was schizophrenic. Scott's father robbed banks. Scott is dangerous, lashing out and attacking staff and other patients whenever he has the chance. Because of his aggressive behavior he is almost always in six-point restraints. Scott was not taking any psychotropic medication when I began working with him. He is THE identified problem in our program. Attempts have been made to transfer Scott to another program in our facility, but no other unit will take him. He is a big man, with large facial features and scars on his face and neck from years of self-abuse. He has few front teeth, presumably because they were knocked out long ago. When not restrained, Scott will hit himself severely on the head, face and back of the neck. Scott uses a wheelchair and can only walk with difficulty due to an injury to his upper vertebrae. It is not known whether Scott injured himself or was injured by another patient.

Scott routinely assaults staff and other patients, using both his fists and his head. When Scott is assaultive the strength of his arms is astonishing. It will typically take three or four staff members to hold his arms down. Scott recently head-butted an occupational therapist, breaking her cheekbone almost through the occipital orbit. It goes without saying that the staff are afraid to work with him. Scott spends much of his screaming. There is no apparent reason for much of Scott's screaming. When his hands are free, Scott will clutch at his head and pull his hair. He does not have any painful medical conditions.

When he is in a good mood Scott laughs to himself for unknown reasons. At times he will focus his attention as if someone is talking to him. Some of the staff believe that he is hearing voices and his behavior seems consistent with this idea. This has led to Scott being diagnosed as both autistic and psychotic. Since he does not speak it is difficult to make a differential diagnosis between the two disorders. Scott is severely developmentally disabled with a number of neuro- 
logical problems that are related to past traumatic injury. There is no way of obtaining a more precise diagnosis outside of an expensive MRI scan. The hospital administration believes this to be unnecessary and does not want to pay for the scan to satisfy my curiosity.

Scott rocks himself constantly throughout the day while staring off into space. He often appears to be in his own world. He does not make much eye contact either except at certain times with certain people. There is also an element of bizarreness in his interactions with other people. In the meantime, he continues to be restrained most days, screaming to the universe. Often when I interact with Scott, his mood will abruptly change. He will go from screaming and clutching his head to suddenly laughing and acting calm. This is often a ruse on his part. Once Scott becomes calm, I have let down my guard and been savagely attacked. It feels as if Scott is trying to kill me. During these episodes Scott seems malevolently intelligent and I have the distinct feeling of another presence inhabiting Scott. The unit physician told me that she thought that in times past Scott would have been diagnosed as "being possessed by demons". I agree.

\subsection{Treatment}

With Jimmy and Scott, in addition to the mandated behavioral treatment regime (which was not initially helpful to either patient) I conducted a form of therapy where the goal was to foster a primitive transference with both individuals. Assuming both Jimmy and Scott were developmentally frozen in a pre-object integration phase, these sessions were an attempt to foster a transitional space to strengthen central identity formation. In Jimmy's case chocolate and coffee may have functioned as transitional objects facilitating a transference. Unlike a patient with normal intelligence, verbal interaction with both Jimmy and Scott was one-way from therapist to patient. I could not rely on reports of dreams, free association, and interpretation to move the therapy forward. What I could do was to try and understand their behavior symbolically. For example, Jimmy's nipple-tweaking attacks could be interpreted as the bad object attacking the good, giving a snapshot of his internal psychic dynamics. Perhaps more importantly, I could encourage a transference through my presence and hope that this would lead to object integration and better identity formation via supportive interpersonal interaction. By remaining calm and present, especially when Jimmy and Scott were prone to violent behavior, they both were able to experience a consistent object different from their chaotic childhood experiences. These encounters functioned as a corrective emotional experience ${ }^{3}$. Secondary gain was also certainly present; both patients received a tremendous amount of attention when in a so-called possessed state. I worked with this behaviorally by not reinforcing violent behavior related to possession.

\footnotetext{
${ }^{3}$ Although this idea not been well accepted in many current psychoanalytic circles, it is being re-evaluated (Christian et al., 2012; Cockburn, 1986; McCarthy, 2010). Corrective emotional experience has been postulated to be reparative in situations where the patient's pathology is related to the search for, and integrations of, the bad object (Knight, 2005). This idea may also be relevant to situations when two-way verbal interaction with the patient is impossible.
} 
I spent an hour a day with both Jimmy and Scott, five days a week. Our sessions together lasted for two years after which they decreased to once or twice a week for six months, and then only as needed. After about two years into this process both Jimmy and Scott showed marked reduction in their violent behavior and the sense of being in the presence of an "other" greatly diminished. It should be noted that one year into Scott's psychotherapy he began pharmaceutical treatment with a standard dose of an SSRI antidepressant and a low dose of an anti-psychotic. However, Scott had been on pharmaceutical treatments many times in the past with no reduction in his violent behavior. Nevertheless, it is possible that Scott's medication regimen may have helped him benefit from our sessions together. Jimmy was not treated pharmaceutically. Follow up assessment two years after my intensive treatment found that both Jimmy and Scott no longer exhibited violent behavior. And although it is unknown whether either Jimmy or Scott achieved internalized object integration and ambivalence, both seemed happier and well-adjusted.

\section{Implications for Clinical Intervention}

As we have seen, a belief that demonic possession is real relies on a specific dichotomous worldview that splits the world into good and bad, black and white, good and evil. As in Peck's cases the clinician who holds this belief understands the patient as being either on team Jesus or team Devil. There is no middle ground, no gray area, no subtlety. With this view, the clinician must rely exorcism or an exorcism-like practice. For the religious mental health worker, like Peck, this could be a religious rite or a secular form of therapy that can be made to conform to a belief that demons are real. Regardless of therapeutic system, this view of treatment is rooted in understanding the patient as being on the wrong side of a dichotomy. The solution, then, becomes how to eliminate the wrong side.

In my mind this approach relies on a simplistic understanding of possession phenomena and is not likely to succeed. Or if it does succeed, the success will be short-lived, and the symptoms of demonic possession will return. All these approaches rely on eliminating the demon via some sort of technique. Exorcism proper invokes the authority of a father image in the form of God or Jesus to drive out or eliminate demons and drive away the bad. This is clinically akin to the authoritative doctor admonishing the patient to keep a stiff upper lip and get better. While it is possible that the obsessive ritual of an exorcism or some forms of psychotherapy may strengthen defenses against anxiety, this does not seem like a good long-term solution. Likewise, a cathartic release during an exorcism or psychotherapy will have good short-term outcomes but will result in a later increase in anxiety and an attempt by patients to re-repress the demonic characteristics or project them out.

Object relations-oriented psychotherapy provides a more subtle approach. A safe assumption is that demonically possessed individuals lack object integration, and function at the level of borderline personality organization. Treatment 
for these individuals does not need to rely on a belief in actual demons or a Devil. It requires an understanding of the intricacies of the internal world of the patient. Through the establishment of a transference with the therapist, the patient can begin to work towards integration of good and bad objects in order to achieve ambivalence and object constancy. This will be a long therapeutic process similar to modern treatment for personality disorders in general and for borderline personality disorder (which has dissociative features) specifically (Caligor et al., 2018; Kernberg, 1980, 1993, 1995; Ogden, 1992; V. Volkan, 2012; V. Volkan, 1977).

Treatment intervention for those with more severe dissociation presenting as demonically possessed will likely require further specialized knowledge and technique. This treatment, like treatment for DID, is painstakingly subtle, requiring the careful re-integration of demons/alters over an extended period of time. Spira (1996), writing in his edited volume on treating dissociative identity disorder details the essential elements of psychotherapy with DID patients which would seem to be applicable to severe cases of demonic possession. These elements include developing rapport, gathering information, communicating with alters, and establishing an interpersonal relationship. Spira discusses how he works with such patients:

"I find it useful to conceive of therapy as being like family therapy to some extent. If I conceptualize many members of the family as having many characteristics similar to borderline personality disorder, I become very sensitive to relevant interpersonal issues. Primary among these are extremes in interpersonal sensitivity such as jealousy, fear of abandonment, and being easily angered by others' actions or lack of action. Therefore, I usually announce why I am speaking with one 'person' rather than another. After settling down with whomever presents in the session, I try to talk first with the alter who most requires assistance for anything major going on. I then ask that alter whether I should know about any concerns that'others' may have. I frequently have the patient go into a hypnotic 'trance', during which I can announce to the 'group' that 'anyone' who wants to speak to me should come out now or let the 'person' who first comes out tell me of his or her desire to speak with me at some point today." (p. xxxvii)

Spira (1996) warns that specialized training is needed to work with people suffering from DID. Working with such severely dissociated patients, is not something that most, even experienced, clinicians face in their careers. There are exceptionally few mental health clinicians specializing in treating dissociative disorders and even fewer working with the demonic possession. Nevertheless, those without training or experience in this area would be wise to seek out consultation if they find themselves working with such patients.

\section{Conclusion}

Demonic possession can be unsettling for clinicians. The cases of Jimmy and Scott are interesting because both of these individuals were developmentally disabled yet demonstrated dissociative phenomenon related to demonic posses- 
sion. This indicates that possession phenomena are not necessarily related to functional intelligence or the achievement of later developmental milestones. It is quite possible that developmental disabilities interfere with identity development. Given that identity development begins as a preverbal interpersonal process, it is not far-fetched to assume individuals like Jimmy and Scott may be mentally frozen at the beginning of identity formation. If a balanced preverbal identity formation process is disturbed, then identity diffusion or even fragmentation is possible (Ermann, 2011). Also, given their early child-backgrounds, it is highly likely that both Jimmy and Scott experienced developmental trauma disorder which could also lead to dissociation (Teague, 2013). For an external observer these characteristics could manifest in something that appears like demonic possession. Dissociative phenomena in developmentally disabled people have not been well studied and would benefit from further research.

In our Western culture it is easy to overlay religious explanations to the sense of being in the presence of an additional "other" in an individual's personality makeup. Even trained healthcare professionals may react this way because many are steeped in a Judeo-Christian worldview. It is easy to experience demonic possession as a dichotomy and blindly react to it. But frightening as it is, there is much to be gained by a psychological approach to understanding and treating demonic possession. Where there were once demons, there can instead be a meaningful encounter with a person's inner psychic world.

\section{Conflicts of Interest}

The author declares no conflicts of interest regarding the publication of this paper.

\section{References}

Bourguignon, E. (1991). Possession. Long Grove, IL: Waveland Press.

Caligor, E., Kernberg, O. F., Clarkin, J. F., \& Yeomans, F. E. (2018). Psychodynamic Therapy for Personality Pathology: Treating Self and Interpersonal Functioning. American Psychiatric Publishing, Inc.

Carroll, R., \& Prickett, S. (Eds.). (2008). The Bible: Authorized King James Version. Oxford: Oxford University Press.

Christian, C., Safran, J. D., \& Muran, J. C. (2012). The Corrective Emotional Experience: A Relational Perspective and Critique. In L. G. Castonguay, \& C. E. Hill (Eds.), Transformation in Psychotherapy: Corrective Experiences across Cognitive Behavioral, $\mathrm{Hu}$ manistic, and Psychodynamic Approaches (pp. 51-67). Washington DC: American Psychological Association. https://doi.org/10.1037/13747-004

Clifford, T. (1996). Tibetan Buddhist Medicine and Psychiatry: The Diamond Healing. Delhi: Motilal Banarsidass.

Cockburn, A. (1986). Review of the Psychology of the Self and Others. Group Analysis, 19, 366-367. https://doi.org/10.1177/0533316486194015

Crook, J. H. (1998). The Indigenous Psychiatry in Ladakh, Part II: Narrative and Metanarrative in the Cultural Control of Dissociative States in the Himalayas. Anthropology \& Medicine, 5, 23-42. https://doi.org/10.1080/13648470.1998.9964547 
De exorcismis et supplicationibus quibusdam (2004). Typis Vaticanis.

Egenes, L., \& Reddy, K. (2016). The Ramayana: A New Retelling of Valmiki's Ancient Epic-Complete and Comprehensive. New York: Tarcher Perigee.

Eliade, M. (2004). Shamanism: Archaic Techniques of Ecstasy (Bollingen Series). Princeton, NJ: Princeton University Press.

Ellenberger, H. F. (1981). The Discovery of the Unconscious: The History and Evolution of Dynamic Psychiatry. New York: Basic Books.

Ermann, M. (2011). Identity, Identity Diffusion, Identity Disorder. Psychotherapeut, 56, 135-141. https://doi.org/10.1007/s00278-011-0813-8

Freud, S. (1908). Character and Anal Erotism. The Standard Edition of the Complete Psychological Works of Sigmund Freud, Volume IX (1906-1908): Jensen's “Gradiva, ” and Other Works (1906-1909). London: Hogarth Press and the Institute of Psychoanalysis.

Freud, S. (1919). Totem and Taboo: Resemblances between the Psychic Lives of Savages and Neurotics (Brill, A.A., Trans.). New York: Moffat, Yard \& Co.

Freud, S. (1923). A Seventeenth-Century Demonological Neurosis. In Standard Edition of the Complete Psychological Works of Sigmund Freud (Vol. 19, pp. 72-105). London: The Hogarth Press and the Institute of Psychoanalysis.

Friedkin, W. (1973). The Exorcist [Horror]. Warner Bros., Hoya Productions.

Gran, S. (2003). Come Closer. New York: Soho Press.

Hacker, P. (1978). Zur Entwicklung der Avataralehre. In L. Schmithausen (Ed.), Kleine Schriften. Wiesbaden: Otto Harrassowitz.

Hansen, F. J., Stanilla, J. K., Ross, J. I., \& Sinvani, C. (1992). Integrating Child Psychiatry and Family Systems Approaches: A Case of Demonic Possession in an Eight-Year-Old Boy. Journal of Family Psychotherapy, 3, 13-26. https://doi.org/10.1300/j085V03N03_02

Hill, S., \& Goodwin, J. R. (1993). Demonic Possession as a Consequence of Childhood Trauma. The Journal of Psychohistory, 20, 399-411.

Ivey, G. (1993). Psychodynamic Aspects of Demonic Possession and Satanic Worship. South African Journal of Psychology, 23, 186-194. https://doi.org/10.1177/008124639302300405

Ivey, G. (2002). Diabolical Discourses: Demonic Possession and Evil in Modern Psychopathology. South African Journal of Psychology, 32, 54-59. https://doi.org/10.1177/008124630203200407

Kernberg, O. F. (1980). Internal World and External Reality: Object Relations Theory Applied. Lanham, MD: Jason Aronson.

Kernberg, O. F. (1993). Severe Personality Disorders: Psychotherapeutic Strategies. London: Yale University Press.

Kernberg, O. F. (1995). Borderline Conditions and Pathological Narcissism. Lanham, MD: Jason Aronson, Inc.

Knight, Z. G. (2005). The Use of the "Corrective Emotional Experience" and the Search for the Bad Object in Psychotherapy. American Journal of Psychotherapy, 59, 30-41. https://doi.org/10.1176/appi.psychotherapy.2005.59.1.30

Krippner, S. (2019). Shamanism and Dreams. In R. J. Hoss, \& R. P. Gongloff (Eds.), Dreams: Understanding Biology, Psychology, and Culture (Vol. 2, pp. 706-710). Westport, CT: Greenwood Press/ABC-CLIO.

McCarthy, M. E. (2010). Corrective Emotional Experience Revisited. The International Journal of Psychoanalysis, 91, 1272-1275.

https://doi.org/10.1111/j.1745-8315.2010.00345.x 
Monier-Williams, M. (1872). A Sanskrit-English Dictionary. Oxford: Clarendon.

Murti, T. R. V. (2013). The Central Philosophy of Buddhism: A Study of the Madhyamika System. Abingdon-on-Thames: Routledge. https://doi.org/10.4324/9780203706701

Ogden, T. H. (1992). The Primitive Edge of Experience. Lanham, MD: Jason Aronson, Inc.

Peck, M. S. (2005). Glimpses of the Devil: A Psychiatrist's Personal Accounts of Possession. New York: Free Press.

Prins, H. (1990). Bizarre Behaviours (Psychology Revivals): Boundaries of Psychiatric Disorder. Abingdon-on-Thames: Routledge.

Richards, J. (1974). But Deliver Us from Evil: An Introduction to the Demonic Dimension in Pastoral Care. London: Darton, Longman and Todd.

Rosik, C. H. (2005). Giving the Devil More than His Due. PsycCRITIQUES.

Satan, Devils, \& Demons (n.d.). Wrested Scriptures. http://wrestedscripture.com/b07satan/satan.html

Sheth, N. (2002). Hindu Avatāra and Christian Incarnation: A Comparison. Philosophy East and West, 52, 98-125. https://doi.org/10.1353/pew.2002.0005

Sidky, H. (2011). The State Oracle of Tibet, Spirit Possession, and Shamanism. Numen, 58, 71-99. https://doi.org/10.1163/156852711X540096

Slaten, A. W. (1920). Did Jesus Believe in Demons? The Biblical World, 54, 371-377. https://doi.org/10.1086/476419

Spanos, N. P., \& Gottlieb, J. (1979). Demonic Possession, Mesmerism, and Hysteria: A Social Psychological Perspective on Their Historical Interrelations. Journal of Abnormal Psychology, 88, 527-546. https://doi.org/10.1037/0021-843X.88.5.527

Spira, J. L. (1996). Treating Dissociative Identity Disorder. San Francisco, CA: Jossey-Bass.

Teague, C. M. (2013). Developmental Trauma Disorder: A Provisional Diagnosis. Journal of Aggression, Maltreatment \& Trauma, 22, 611-625. https://doi.org/10.1080/10926771.2013.804470

Turner, V. W. (1979). Aspects of Saora Ritual and Shamanism: An Approach to the Data of Ritual. In A. L. Epstein (Ed.), The Craft of Social Anthropology (pp. 181-204). Oxford: Pergamon. https://doi.org/10.1016/B978-0-08-023693-3.50013-2

Van den Stock, J., Vandenbulcke, M., Zhu, Q., Hadjikhani, N., \& de Gelder, B. (2012). Developmental Prosopagnosia in a Patient with Hypoplasia of the Vermis Cerebelli. Neurology, 78, 1700-1702. https://doi.org/10.1212/WNL.0b013e3182575130

Volkan, K. (1994). Dancing among the Maenads: The Psychology of Compulsive Drug Use. Frankfurt am Main: Peter Lang Publishing.

Volkan, V. (2012). Psychoanalytic Technique Expanded: A Textbook on Psychoanalytic Treatment. Durham, NC: Pitchstone Publishing.

Volkan, V. D. (1977). Six Steps in the Treatment of Borderline Personality Organization. Lanham, MD: Jason Aronson, Inc. 